\title{
ENTRE ‘HESTÓRIAS’ E ‘PRÍNCEPES’, A HIPERCORREÇÃO NA ESCRITA REVELA O QUE AS CRIANÇAS SABEM SOBRE A LÍNGUA
}

\author{
Taise Simioni \\ Larissa Ferraz Noble
}

\begin{abstract}
RESUMO
Esta pesquisa tem por objetivo analisar, qualitativamente, os erros de hipercorreção obtidos na escrita de crianças do $2^{\circ}$ ano do ensino fundamental de uma escola pública da cidade de Bagé/RS. Com a análise dos dados, percebemos que os erros não são aleatórios e revelam os conhecimentos linguísticos das crianças, em especial aqueles referentes à variação linguística.
\end{abstract}

PALAVRAS-CHAVE: hipercorreção; oralidade/escrita; variação linguística.

\section{Introdução}

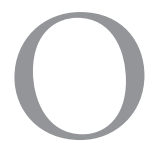

presente trabalho tem como tema o fenômeno da hipercorreção na escrita de crianças do $2^{\circ}$ ano do ensino fundamental de uma escola pública da periferia da cidade de Bagé/RS. O principal objetivo desta pesquisa é analisar, qualitativamente, os dados de hipercorreção obtidos por meio de dois testes, descritos a seguir na seção de metodologia. Esperamos mostrar em nossa análise que os erros por hipercorreção demonstram a reflexão das crianças sobre a língua escrita em sua relação com a língua falada.

Partimos da hipótese de que a fala e a escrita estão intimamente ligadas, contudo ambas possuem características que as diferem. Conforme Leal e Roazzi (2000), a criança começa a entender o sistema da escrita quando percebe que oralizamos "tudo" que escrevemos e vice-versa. A criança evolui 
ao tentar recriar os sons da fala, porém só continuará evoluindo se perceber que a escrita não é idêntica à fala. Neste sentido, percebemos a importância de não conceber o erro ortográfico como um mal a ser abolido, mas sim como uma ferramenta privilegiada de conhecimento para o professor. Para isso, o professor deve ser conhecedor das questôes linguísticas, de maneira geral, e de variação linguística, de modo mais específico, pois terá mais condiçôes de entender as complexidades implicadas no ensino de uma língua, conforme Mollica (2000).

A seguir, veremos a seção destinada à fundamentação teórica, a qual se divide em três momentos: relação entre fala e escrita; a noção de erro; e, por fim, a formação do professor. Em seguida, apresentamos a metodologia, a seção que se dedica à análise dos dados e, para encerrar, as considerações finais.

\section{Fundamentação teórica}

Nas três próximas seçóes, apresentamos o suporte teórico que fundamenta nossa análise sobre hipercorreção. Para iniciar, expomos algumas questóes básicas sobre as relações entre a fala e a escrita. Na sequência, explicitamos a concepção de erro adotada neste trabalho. Por fim, destacamos a importância da formação linguística para os professores de séries iniciais e, também, para os professores de línguas.

\section{Relação entre fala e escrita}

Segundo Zorzi (1998, p. 21), a relação entre escrita e oralidade pode ser tratada "de um ponto de vista da oralidade para a escrita ou da escrita para a oralidade". Nos estágios iniciais de aquisição da escrita, a oralidade pode ser entendida como a primeira língua que serve de apoio para o primeiro nível de escrita. Nesta perspectiva, incialmente, a oralidade influenciaria muito a escrita ${ }^{1}$. Ainda Zorzi (1998, p. 21) nos diz que, "na medida em que a escrita

1 Registramos, aqui, a visão de Abaurre (1999), que não concorda com essa relação de forte dependência entre a escrita e a oralidade nos estágios iniciais de aquisição da escrita. A autora defende a hipótese de que "a modalidade escrita é autônoma com relaçáo à modalidade oral, mas, em certas circunstâncias, pode haver uma interação entre os fatos da oralidade e as formas que assume a escrita. [...] Observe-se que a assunção de tal hipótese não implica, de forma alguma, que as crianças tenham algum tipo de consciência dos aspectos fônicos da 
vai se tornando mais independente da oralidade e adquirindo as características formais que a definem como língua padrão [...], [a escrita] pode produzir transformações na própria oralidade" ${ }^{2}$. Neste momento, ocorre uma inversão: a escrita serviria de "apoio" à oralidade. Fica evidente, assim, que fala e escrita estão intimamente relacionadas, mantendo, entretanto, características que as distinguem enquanto sistemas.

Para Faraco (2012), um dos grandes desafios de quem aprende a escrever é adequar a língua escrita a uma enorme gama de recursos da língua falada, ou seja, ir da infinidade de recursos da oralidade (apoio gestual e facial, recursos prosódicos, etc.) para a escassez de recursos da escrita. Esta relação entre a fala e a escrita pode ser tratada de uma maneira equivocada no ensino. Cagliari (2009) destaca que a escola leva o aluno a pensar que a linguagem escrita é a correta e a linguagem falada é confusa e incompleta. $\mathrm{O}$ autor ressalta que estes são dois usos diferentes, cada um com seus aspectos próprios e finalidades próprias.

$\mathrm{Na}$ escola, após compreender como funciona o sistema de escrita do português e perceber as relações mais amplas entre este sistema e a fala, um novo desafio se impóe: os aspectos ortográficos da língua. Como já mencionado, Leal e Roazzi (2000, p. 101) dizem que "a criança começa a entender os princípios do sistema alfabético quando ela percebe que a escrita pode ser oralizada e que escrevemos 'tudo' que oralizamos”. É assim que a criança começa a descobrir as regras do sistema e tenta representar a sílaba oralizada na fase silábica

sua língua e que objetivem representá-los na escrita. A hipótese, conforme formulada, prevê apenas a possibilidade de algum 'vazamento' do oral para o escrito, algo que pode escapar completamente às intençóes e ao controle de quem escreve" (ABAURRE, 1999, p. 174).

2 Abaurre (1988) discute uma situação em que a escrita pode transformar não diretamente a oralidade, mas as representaçóes subjacentes à fala. Segundo a autora, dados de escrita inicial conduzem à hipótese de que as crianças assumem a existência de vogais nasais subjacentes em português em palavras como canto e vendaval. $\mathrm{O}$ contato com a escrita e a leitura poderia, posteriormente, fazer com que houvesse uma reestruturação das representações fonológicas, no sentido de que as crianças passariam a interpretar as vogais nasais com uma sequência de vogal seguida de um segmento nasal. Esta discussão deixa muito clara a importância da análise de dados de aquisição da escrita para a discussão de questóes teóricas em linguística. Neste mesmo sentido, Amaral e Gonçalves (2013) defendem a ideia de que as crianças passam por uma reestruturação da representaçáo fonológica dos ditongos decrescentes variáveis (como em faixa e beira) em função do contato com a escrita. Segundo as autoras, inicialmente, o ditongo seria representado subjacentemente por apenas uma vogal e, posteriormente, a partir do contato com a escrita, o ditongo passaria a ser interpretado como uma sequência de vogais subjacentes. 
de aquisição da escrita (FERREIRO e TEBEROSKY, 1999). Porém, ao chegar ao nível alfabético, a criança é requisitada a não utilizar, na escrita, a fala tal qual como ocorre. Se por um lado a criança evoluiu ao tentar reproduzir os sons da fala, por outro só continuará evoluindo se perceber que a escrita não é fiel à fala. Neste sentido, Rego e Buarque (2000, p. 22) apontam que o sistema ortográfico do português é de base alfabética, ou seja, em princípio, as letras representam as unidades sonoras da palavra. Sendo assim, em um sistema de escrita desta ordem, cada letra deveria representar um som e cada som uma letra. Contudo, no português são poucos os casos em que esta regularidade simples está presente. São vários os casos em que essas regularidades são mais complexas e exigem análises mais sutis do escrevente (cf. BARBOSA DA SILVA, 1981; LEMLE, 2009).

Conforme Rego e Buarque (2000), há um consenso entre alguns pesquisadores no que diz respeito ao progresso da criança ao entrar na fase alfabética. A escrita das crianças mostra que erros de naturezas opostas coexistem entre si, como erros por transcrição de fala (em que é registrada a fala na escrita) ocorrendo em um mesmo indivíduo com erros de hipercorreção ${ }^{3}$ (em que são feitas generalizaçóes inadequadas na escrita). Como exemplificam os autores, podemos encontrar "buli" para "bule" ao lado de "cel" para "céu". Na próxima seção, explicitaremos de que maneira compreendemos o erro, de maneira mais ampla, e, por consequência, o erro por hipercorreção neste trabalho.

\section{A noção de erro}

Mollica (2000), que discute sobre a questão da variação linguística e suas implicaçóes para o ensino da língua, tanto a falada quanto a escrita, afirma que a noção de erro dependerá da posição assumida pelo professor. Ao se adotar um posicionamento prescritivista, todo e qualquer emprego linguístico que for de encontro ao que diz a norma gramatical ou a norma culta deve ser combatido e eliminado dos enunciados falados e escritos. Ao se adotar um posicionamento descritivista, colocaçóes atípicas e certos usos serão considerados naturais ou inadequaçóes (desde que se tenha como referência a norma culta). Segundo a autora, a segunda posição faz com que sejam introduzidos

3 Os autores usam o termo "supercorreção". 
"o respeito e a aceitação a qualquer manifestação da língua, desde que compreendida como própria a usos diversos, que invocam dialetos e/ou estilos linguísticos diferentes, igualmente possíveis e previsíveis aos falantes de uma língua” (MOLLICA, 2000, p. 16).

No que diz respeito especificamente à língua escrita, se concebermos sua aquisição como um processo de formação de conhecimentos, os erros que aparecem nas produçôes escritas das crianças serão indicativos da apropriação de uma nova linguagem e demonstrarão que elas podem estar formulando hipóteses para a escrita, de acordo com Zorzi (1998). Portanto, os erros, muitas vezes tomados como algo que indica problemas de aprendizado, passam a ser vistos como inerentes ao processo de mudança de um sistema oral para um sistema escrito de linguagem, segundo o autor. Nesta segunda perspectiva, "os erros podem corresponder a tentativas de compreender e dar sentido às propriedades características do sistema de escrita” (ZORZI, 1998, p. 20).

Leal e Roazzi (2000) destacam que os erros observados em crianças em processo de aquisição da escrita são reflexos não apenas do que elas ainda não sabem do sistema escrito, mas do que elas já sabem dele também ${ }^{4}$. Visto por essa perspectiva, o erro se torna uma ferramenta privilegiada de informação para que o professor possa compreender e conhecer as estratégias utilizadas pelos alunos e também a origem dos conhecimentos aplicados, o que permitirá ao professor elaborar intervençóes didáticas adequadas. Esta é uma perspectiva também defendida por Teixeira, Grassi, Oliveira e Miranda (2011). As autoras destacam a importância da formação linguística do professor neste processo. Este assunto será abordado na próxima seção.

Massini-Cagliari (1999) mostra que é preciso olhar mais atentamente para os erros ortográficos. A autora aponta que há duas possíveis maneiras de concebê-los. Uma delas é lidar com eles como se representassem a escrita fonética, a manifestação de um desejo de transcrever a fala como ela se realiza.

4 Morais (2000) deixa muito clara esta questão ao analisar a escrita de alunos em séries iniciais para verificar a correlação entre seu desempenho em ortografia e o que são capazes de verbalizar sobre seu conhecimento do sistema ortográfico. Segundo Morais (2000, p. 79), "aprender a escrever ortograficamente não é um processo passivo, memorístico, de simples estocagem das imagens corretas das palavras. Os próprios erros infantis que revelam certas 'regularizaçóes' (por exemplo, *bunitu) ou hipercorreções (por exemplo, *cel, no lugar de céu) demonstram que o aprendiz está processando ativamente as propriedades da ortografia, construindo suas representaçóes internas sobre os modelos de escrita correta que encontra no mundo". 
Outra seria vê-los como uma reflexão produtiva e construtiva acerca do próprio sistema de escrita. A autora mostra que, mesmo nos casos em que a escrita parece ser uma transposição da fala, como na escrita "primero" (por "primeiro'), é preciso levar em consideração que a criança pode ter feito uma escolha entre as diferentes formas de se grafar um ditongo: a escrita registra um ditongo que não ocorre na fala ("couro", "cheiro", "vou”); a escrita registra um ditongo que de fato ocorre na fala ("mais", "meu”, "boi”); a escrita não registra um ditongo que ocorre na fala ("mas", "paz", "vez"). Massini-Cagliari (1999, p. 126) conclui afirmando que "pode-se também elaborar a hipótese, aliás mais provável, de que, diante destes fatos do sistema de escrita, o aprendiz teve de fazer uma opção - que, infelizmente, não correspondeu à forma ortográfica estabelecida para esta palavra”.

Para este trabalho, concebemos o erro ortográfico não como um mal que deve ser combatido insistentemente pelo professor, mas como uma ocorrência inerente ao processo de aquisição da língua escrita. Não se trata, portanto, de um problema que precisa ser solucionado, mas de um indicativo precioso para o professor de como a criança está concebendo o sistema de escrita, no sentido de que os erros evidenciam as hipóteses que estão sendo formuladas pelas crianças. Interpretamos, então, as grafias não convencionais como "lugares privilegiados de observação da relação do sujeito com a linguagem" (TENANI e REIS, 2011, p. 28). Para conceber o erro desta forma e saber o que fazer com as informaçóes que eles fornecem, o professor precisa de uma série de conhecimentos, como será evidenciado na próxima seção.

Neste trabalho, analisaremos os erros por hipercorreção. Cabe mencionar que este fenômeno recebe diferentes nomenclaturas na literatura. Por um lado, temos autores que utilizam o termo aqui empregado, "hipercorreçáo", como Cagliari (2009), Tenani e Reis (2011) e Silva (2011). Por outro lado, temos autores como Zorzi (1998), que usam o termo "generalização de regras", Rego e Buarque (2000), que empregam "supercorreção", e Lima, Dhein e Miranda (2008), que utilizam "supergeneralização". Independentemente do termo empregado, todos concebem o fenômeno como um caso em que o escrevente mostra que apreendeu uma regra do sistema de escrita, como, por exemplo, o fato de que a escrita registra a letra <e> para o que é realizado na fala pelo som [i], como na palavra "vestido". Ele, então, aplica esta regra a contextos indevidos, como na palavra "história" escrita como "hestória". A 
hipercorreção, por sua natureza, é de suma importância para o professor, porque demonstra, de maneira inequívoca, que o escrevente apreendeu determinada regra, embora eventualmente a use em contextos em que ela não se aplica, em função do caráter arbitrário do sistema de escrita. De maneira muito evidente, a hipercorreção mostra o que o aluno sabe. Aplicamos, assim, à aquisição da escrita o que Menn e Stoel-Gammon (1997, p. 287-288) afirmam sobre a aquisição da fala: "a supergeneralização de uma regra a casos em que ela não deveria ser aplicada é tomada (aqui e em outros trabalhos) como o marco da verdadeira aprendizagem da regra”.

\section{A formação do professor}

Mollica (2000) mostra que alguns dos interesses da pesquisa linguística está na formação do professor e numa aprendizagem eficaz do aluno na escola. No que diz respeito à formação do professor, a autora esclarece que um profissional ciente das questóes de variação linguística e, portanto, conhecedor das potencialidades linguísticas de um falante terá mais condições de compreender as dificuldades envolvidas no processo de ensino de uma língua. Segundo Mollica (2000, p. 17), "o professor mais consciente torna-se, sem dúvida, um profissional com maiores chances de propor soluçóes aos desafios”. No que diz respeito à aquisição de uma língua pelo falante e às contribuiçóes que pode trazer um ensino em que se discutem a variação linguística e seus condicionamentos, a autora aponta que "tomar conhecimento dos usos linguísticos, de suas adequaçóes e inadequaçóes, e desenvolvê-los de forma sistemática constituem as pré-condiçóes fundamentais à aquisição e desenvolvimento de uma língua escrita e falada em toda a sua plenitude" (MOLLICA, 2000, p. 17).

Segundo Cagliari (2009), o conhecimento das teorias linguísticas é imprescindível à prática do professor, para que o auxiliem em sala de aula. $\mathrm{O}$ autor destaca, entretanto, que tais teorias não correspondem a uma metodologia de ensino: "o uso da linguística no ensino de português tem que ser planejado em conjunto por linguistas e professores, com a colaboração de pedagogos, psicólogos etc." (CAGLIARI, 2009, p. 36). O linguista mostra o conteúdo e o professor de português, junto com seus colaboradores, dosa o ensino, programa-o na sequência conveniente e busca motivaçóes e significaçóes para o aluno estudar português, de acordo com Cagliari (2009). 
Ainda segundo Cagliari (2009), quanto mais conhecedor for o professor do processo de aquisição de conhecimento, mais oportunidades este terá de conduzir de forma agradável e produtiva o processo de aprendizagem. Sendo assim, o professor terá liberdade de eleger metodologias e técnicas, pesquisar rumos e adequar o ritmo de acordo com sua turma.

No que se refere especificamente à língua escrita, Zorzi (1998) salienta que o professor ocupa um lugar privilegiado de mediador entre a criança e a escrita. Para que essa função possa ser exercida, o professor necessita compreender a fundo a construção de conhecimento das crianças, bem como aprofundar seus próprios conhecimentos acerca da escrita. Ainda, Zorzi (1998, p. 108) atenta para o fato de que, "certamente, entendendo melhor a complexidade da própria escrita e todos os desafios que ela impóe [...], o educador [pode] compreender de maneira mais adequada a escrita que as crianças produzem e, assim, valorizá-las porque podem estar denotando um grande esforço de compreensão". O autor defende que os professores devem falar explicitamente sobre as características da escrita, como, por exemplo, as relaçôes múltiplas entre sons e letras e as diferenças entre falar e escrever. Segundo o autor, as "regras do jogo da escrita" precisam ser discutidas abertamente com as crianças. Isto só será possível se o professor tiver os conhecimentos necessários para conduzir esta discussão.

Massini-Cagliari e Cagliari (1999) destacam, em vários momentos de sua obra, a importância de o professor conhecer a história da escrita e da ortografia, bem como o funcionamento do sistema de escrita, o que inclui o sistema ortográfico. Desta forma, ele estará habilitado para propor intervençóes pedagógicas bem fundamentadas no sentido de auxiliar os alunos a superarem suas dificuldades. Como ressalta Cagliari (2009, p. 36), "o professor de português tem que ser um profissional competente, tem que conhecer profundamente a língua portuguesa”.

Nas próximas seções, traremos uma análise da hipercorreção que levará em conta conhecimentos sobre o sistema fonológico da língua portuguesa, sobre a relação entre a fala e a escrita e sobre a variação fonológica. Defendemos, aqui, a importância de os professores de séries iniciais e de língua portuguesa terem acesso a estes conhecimentos para que possam compreender as produçóes de seus alunos e, desta forma, buscar métodos que auxiliem, de maneira qualificada e cientificamente embasada, os alunos a superarem suas dificuldades. 


\section{Metodologia}

A coleta de dados para esta pesquisa foi realizada com alunos de duas turmas de $2^{\circ}$ ano de Ensino Fundamental, em uma escola municipal localizada na periferia do município de Bagé/RS. Tal coleta ocorreu no primeiro semestre do ano de 2014.

Foram aplicados dois testes em um grupo de 16 crianças. No primeiro teste, foram apresentadas oito figuras representando açôes. A instrução dada foi a de que os alunos deveriam descrever por escrito o que estavam vendo na imagem. Foram selecionadas imagens que julgamos ser significativas para as crianças.

Quanto ao segundo teste, este consistiu na leitura da história "Até as princesas soltam pum", de Ilan Brenman (2008). Optamos por uma história presumidamente não conhecida pelos alunos, a fim de que se diminuíssem as chances de as crianças escreverem palavras "decoradas". O segundo critério para a seleçâo do livro foi a expectativa de a história envolver os alunos para que eles participassem ativamente do que estava sendo proposto. Em uma das turmas, $\mathrm{o}$ livro foi lido duas vezes porque os alunos manifestaram que não haviam compreendido a história na primeira leitura. Na outra turma, os alunos, ao contrário do que havíamos esperado, já conheciam a história. Entretanto, como haviam lido o livro no ano anterior, tendo, portanto, uma distância temporal considerável entre os dois contatos com o livro, acreditamos não ter havido um prejuízo à consistência dos dados. Após ouvirem a história, foi solicitado que a contassem por escrito, com todos os detalhes de que se lembrassem.

Após a realização dos dois testes, foram retiradas das produçôes dos alunos todas as palavras em que ocorreu hipercorreçáo $0^{5}$. Foram, ao total, 16 palavras, a partir das quais procederemos a uma análise qualitativa na próxima seção.

\section{Análise dos dados}

Autores como Abaurre (1988) e Miranda (2011) mostram que dados de aquisição da escrita podem revelar os conhecimentos das crianças sobre o sistema fonológico da língua. Ambas as autoras defendem, por exemplo, que os erros de escrita inicial dáo evidências para a assunçấo de que as vogais nasais

5 Os resultados aqui apresentados são um recorte de uma pesquisa que analisou, de maneira abrangente, os erros de escrita decorrentes da variação linguística na fala. 
estão presentes na representação subjacente das crianças, o que traz novos elementos para a discussão sobre a controversa questão da nasalidade vocálica em português. Segundo Miranda (2011, p. 264), no processo de aquisição da escrita, "vão ocorrer 'vazamentos' desse conhecimento linguístico construído pela criança desde seus primeiros contatos com a língua, os quais podem ser observados em erros que envolvem tanto aspectos segmentais como prosódicos".

Pretendemos com nossa análise mostrar que os erros de hipercorreção podem revelar, além de uma percepção sobre as relaçóes entre a fala e o sistema de escrita, uma grande sensibilidade das crianças aos fenômenos variáveis da língua, revelando, assim, uma parte de seus conhecimentos linguísticos.

O Quadro 1 apresenta as categorias em que foram divididos os erros por hipercorreção que constituem nosso corpus.

Quadro 1 - Categorias de erros por hipercorreção

\begin{tabular}{|c|c|}
\hline Categoria & Dados \\
\hline $\begin{array}{l}\text { 1. Troca de }<\mathrm{i}>\text { por }<\mathrm{e}>\text { ou de }<\mathrm{u}>\text { por }<0>\text { em posição } \\
\text { pretônica }\end{array}$ & $\begin{array}{c}\text { hestória (história) } \\
\text { enteiro (inteiro) } \\
\text { luchoosas (luxuosas) } \\
\text { agoentou (aguentou) }\end{array}$ \\
\hline 2. Troca de $<u>$ por $<0>$ em posiçáo tônica ${ }^{6}$ & pom (pum) \\
\hline 3. Troca de $<\mathrm{i}>$ por $<\mathrm{e}>$ em posição postônica não final $^{7}$ & $\begin{array}{l}\text { prinsepe (príncipe) } \\
\text { princepi (príncipe) }\end{array}$ \\
\hline 4. Troca de $<\mathrm{u}>$ por $<\mathrm{l}>$ & $\begin{array}{c}\text { soltol (soltou) } \\
\text { soutol (soltou) } \\
\text { el (eu) } \\
\text { del (deu) } \\
\text { perguntol (perguntou) } \\
\text { pegol (pegou) } \\
\text { levol (levou) } \\
\text { dormil (dormiu) } \\
\text { comel (comeu) }\end{array}$ \\
\hline
\end{tabular}

6 Não houve dados de troca de <i> por <e > em posição tônica.

7 Não houve dados de troca de $<$ u $>$ por $<$ o $>$ em posição postônica. 
Os dados do Quadro 1 revelam que os alunos perceberam a não biunivocidade (mencionada acima) entre letras e sons, ou seja, sabem que uma letra pode representar mais de um som e um som pode ser representado por mais de uma letra. As categorias 1, 2 e 3 mostram que os alunos refletiram sobre o sistema ortográfico do português e estabeleceram as regras em (1) e (2), a partir de dados como "vestido" e "coruja", que podem ser realizados como "v[i] stido" e "c[u]ruja”, respectivamente.

(1)

O que é realizado na fala como [i] pode ser representado na escrita com a letra $<$ e $>$.

(2)

O que é realizado na fala como $[\mathrm{u}]$ pode ser representado na escrita com a letra $<0>$.

Por sua vez, a categoria 4 revela a construção da regra em (3), baseada em dados como "soldado" e "avental", que podem ter as realizaçóes "so[w] dado" e "aventa $[\mathrm{w}]$ ", respectivamente.

(3)

O que é realizado na fala como $[\mathrm{w}]$ pode ser representado na escrita com a letra $<$ l $>$.

A hipercorreção ocorre quando as regras em (1), (2) e (3) são aplicadas em contextos indevidos. O que vamos analisar a partir de agora é o fato de que não parece aleatória a seleção das palavras em que ocorre a hipercorreção.

Em primeiro lugar, é preciso mencionar a ausência do fenômeno sob análise no contexto postônico final. Isto ocorre, como destaca Miranda (2008), porque o português seleciona sistematicamente as letras $<\mathrm{e}>\mathrm{e}<\mathrm{O}>$ para representar, neste contexto, as vogais que nos interessam, não havendo, portanto, espaço para a hipercorreção, apenas para a transcrição fonética (como a escrita "bolu" para a palavra "bolo") 8 .

8 Miranda (2008) traz como exemplos de palavras que fogem a esta regularidade: "lazúli", "báli" e "dándi". Muito provavelmente, estas palavras não pertencem ao vocabulário das crianças. 
Passemos à análise dos dados apresentados no Quadro 1. Com relação à categoria 1 , troca $\mathrm{de}<\mathrm{i}>$ por $<\mathrm{e}>$ ou $\mathrm{de}<\mathrm{u}>$ por $<\mathrm{o}>$ em posição pretônica, percebemos que os dois contextos em que a hipercorreção ocorre correspondem a dois daqueles em que a elevação da vogal média é praticamente categórica na fala, conforme Tenani e Reis (2011). Para sua análise, as autoras, que discutem tanto a hipercorreção quanto a transcrição fonética de vogais em contexto pretônico, tomam os seguintes contextos como aqueles de elevação praticamente categórica na fala: (i) /e/ seguido de /N/ ou /S/ (como em "emprego" e "esperto"); (ii) /e, o/ em contexto de hiato, como em "cadeado" e "moeda"; e (iii) a sílaba "des", como em "desempregado" e "desmaiar". Com relação a nossos dados, "hestória" e "enteiro" pertenceriam ao tipo (i), enquanto "luchoosas" e "agoentou" ao contexto (ii). Levantamos, assim, a hipótese de que as crianças percebem, de maneira inconsciente, quais são os contextos em que a elevação da vogal média pretônica é mais provável de ocorrer na fala e supóem que há uma maior probabilidade de estas palavras serem escritas com $<\mathrm{e}, \mathrm{o}\rangle$, embora sejam realizadas com [i, u]. Registramos que a análise de Tenani e Reis (2011) revelou que a hipercorreção foi maior nos contextos de elevação praticamente categórico do que nos contextos de elevação variável ${ }^{9}$.

Como pode ser observado no Quadro 1, a categoria 2, troca de $<\mathrm{u}>$ por $<0>$ em posição tônica, é constituída de apenas uma palavra. Seguindo nossa linha de raciocínio, isto seria esperado, tendo em vista que não ocorre elevação de vogais médias em sílaba tônica na fala. Este é o único contexto, segundo Camara Jr. (1970), em que as sete vogais do português - /a, é, e, i, ó, o, u/ - mantêm sua capacidade distintiva, havendo uma neutralização nas demais pautas acentuais (pretônica e postônica final e não final) ${ }^{10}$.

Buscaremos explicar por que ocorre hipercorreção em um contexto em que a elevação da vogal média não é possível em português, logo não haveria motivos para a criança pensar que o som $[\mathrm{u}]$, nesta palavra, poderia ser representado pela

9 Schwindt (2002) e Monaretto (2013), que analisam, respectivamente, a harmonização vocálica e a elevação da vogal média sem motivo aparente, reforçam o caráter especial das sequências /eN/ e /eS/ ao optarem por sua exclusão, uma vez que tinham por objetivo discutir um fenômeno variável e estas sequências apresentam uma elevação praticamente categórica. Para uma discussão sobre as diferenças de comportamento linguístico entre a harmonizaçáo vocálica e a elevação sem motivo aparente, sugerimos a leitura de Bisol (2009, 2013).

10 Para uma redefinição das neutralizaçóes propostas por Camara Jr. (1970), sugerimos a leitura de Bisol (2003). 
letra $<\mathrm{o}>$. Em muitas línguas, ocorre o fenômeno da palavra mínima (cf. KENSTOWICZ, 1994), segundo o qual são evitadas palavras lexicais constituídas por apenas uma sílaba ou por apenas uma mora (em línguas sensíveis ao peso ${ }^{11}$ ). Embora o português permita tais palavras (como "pá", "fé", "pó”), elas ocorrem em número reduzido. Nesta língua, a maioria das palavras monossilábicas é destituída de acento, ou seja, são clíticos (como "com”, “de”, “”). A semelhança da palavra "pum" com a palavra "com", por exemplo, que pode ser realizada com elevação ("c[ug]m"), poderia ter levado a criança a interpretar "pum” como uma palavra destituída de acento e, portanto, passível de ser constituída por uma vogal média que sofre elevação. Obviamente, precisamos de mais dados para verificar a validade desta explicação. De qualquer forma, não podemos ignorar o fato de que a sílaba tônica foi alvo de hipercorreção em apenas uma palavra.

Quanto à categoria 3, troca de <i $>$ por $<$ e $>$ em posição postônica não final, temos duas escritas diferentes para a mesma palavra: "prinsepe" e "princepi”. Conforme mostramos anteriormente, Rego e Buarque (2000) destacam o fato de que a mesma criança pode apresentar erros por hipercorreção e por transcrição fonética. Na palavra "princepi", a criança aplica os dois processos na mesma palavra (o mesmo ocorrendo com "soutol", da categoria 4). Passemos à análise destas palavras. Conforme Vieira (2002) ${ }^{12}$, a elevação da vogal média /e/ postônica não final é favorecida em dois contextos na fala: (i) quando a consoante precedente é /s/ ou /z/ (como em "cócega") 13; e (ii) quando a vogal tônica da palavra é alta (como em "número"). Não acreditamos que seja coincidência o fato de que a palavra "príncipe" tenha os dois contextos favorecedores à elevação da vogal média: o contexto precedente à vogal é /s/, e a vogal tônica é /i/. Nossa hipótese, portanto, é a de que a criança percebe, de maneira inconsciente, que estes dois contextos são favorecedores à elevação da vogal média postônica não final e acredita que o mais provável é que esta palavra tenha uma vogal /e/, representada por <e> e realizada como [i].

11 Não há consenso na literatura sobre o português ser ou não uma língua sensível ao peso. Bisol (1992), por exemplo, defende que o português apresenta sensibilidade ao peso, enquanto Lee (1994) contesta tal sensibilidade.

12 Vieira (2002) analisou dados de cidades dos três estados da região sul: Porto Alegre, Flores da Cunha, São Borja e Panambi, no Rio Grande do Sul; Florianópolis, Blumenau, Lages e Chapecó, em Santa Catarina; Curitiba, Londrina, Pato Branco e Irati, no Paraná.

13 Vieira (2009), que analisou dados de Porto Alegre, Florianópolis e Curitiba, confirma que as coronais fricativas favorecem significativamente a elevação da vogal /e/ postônica não final. 
No que diz respeito à categoria 4 , troca $\mathrm{de}<\mathrm{u}>$ por $<\mathrm{l}>$, é preciso, em primeiro lugar, atentar para o fato de que ela é constituída por verbos (com exceção de "el"). Os demais ditongos que constituem o corpus foram escritos em sua forma ortográfica padrão (como "aula", "pouco" e "seu”) ou sofreram monotongação, que ocorreu em apenas três formas ("dismaio" para "desmaiou"; "perto" para "apertou”; "entro" para "entrou”). Das oito formas verbais que apresentam hipercorreção, cinco são produzidas por apenas uma criança. As demais são produçóes de três crianças diferentes.

Alguns dados nos levam a levantar a hipótese de que os alunos que produziram erros da categoria 4 instituíram a regra de que o morfema de $3^{\text {a }}$ pessoa do singular no pretérito perfeito é escrito com vogal mais $<\mathrm{l}>$. O primeiro dado é o fato de que a hipercorreção deste tipo ocorreu quase exclusivamente em verbos. O segundo dado diz respeito à forma "soutol", produzida pela criança que concentrou as palavras da categoria 4. É possível perceber que o ditongo da primeira sílaba é representado por vogal mais $<\mathrm{u}>$, o que poderia ter sido a estratégia adotada para a sílaba final também. A opção por uma estratégia diferente aponta para a interpretação deste pedaço final de palavra como "especial” em função de sua natureza morfológica. Por fim, chama atenção a questão de que o ditongo [ow] derivado de /ou/ apresenta uma monotongação praticamente categórica (PAIVA, 1996; MOLLICA, 2000), como revelam as realizaçóes "toro" e "poco" para "touro" e "pouco", respectivamente, enquanto o ditongo [ow] derivado de /ol/ não sofre monotongação, conforme mostram as palavras "soldar" (*“sodar") e "folgado" (*“fogado"). Assim, partindo do pressuposto de que as crianças, como falantes nativas do português, sabem disso, é estranho encontrar uma grafia como "perguntol" para uma forma que é realizada como "pergunt[o]", ou seja, neste caso, excepcionalmente, haveria uma monotongação derivada de uma vogal seguida por /1/. A hipótese, mais uma vez, é a de que esta excepcionalidade possa ser fruto do reconhecimento da função morfológica da sequência de segmentos na palavra. Como no caso da hipercorreção da categoria 2, apresentamos esta hipótese de maneira incipiente, acreditando que ela mereça ser mais bem estudada.

Como foi possível perceber, as formas com hipercorreção mostram muito mais o que as crianças sabem do que o que elas não sabem. Tais formas revelam seus conhecimentos sobre: (i) as relaçóes entre a língua falada e a língua escrita; (ii) aspectos do sistema fonológico (e morfológico) da língua; 
e (iii) questôes relacionadas à variação linguística. Defendemos, assim, a ideia de que somente professores com conhecimentos em linguística serão capazes de reconhecer e devidamente valorizar os conhecimentos que os alunos, como falantes nativos, têm sobre a língua.

\section{Considerações finais}

Neste artigo analisamos dados do fenômeno da hipercorreção na escrita. Os erros por hipercorreção ocorrem pela aplicação equivocada de regras ortográficas já aprendidas. Como pudemos perceber, tais erros não são erros aleatórios, pois há uma motivação por trás de cada um. Percebemos também que as crianças envolvidas refletem e criam hipóteses acerca da língua escrita.

Como vimos, os erros por hipercorreção são resultados da percepção da não biunivocidade entre letras e sons. As crianças elaboram as próprias regras a partir de palavras já conhecidas e as aplicam em contextos indevidos. Os erros de escrita revelam não apenas o que elas ainda não sabem do sistema escrito, mas também o que elas já sabem sobre ele, conforme Leal e Roazzi (2000), como foi destacado anteriormente.

Análises como a que empreendemos permitem aos professores conhecer as estratégias utilizadas por seus alunos e, assim, propor atividades voltadas às eventuais dificuldades. Conforme foi apontado, a hipercorreção é de extrema importância para o professor, porque demonstra que o escrevente apreendeu determinada regra, embora ocasionalmente a use em contextos em que ela não se aplica. Salientamos, mais uma vez, a importância de termos professores conhecedores das questóes linguísticas e, dentro destas, daquelas relacionadas à variação linguística, pois, conforme destacamos anteriormente, estes terão mais condições de compreender as dificuldades envolvidas no processo de ensino e aprendizagem de uma língua, de acordo com Mollica (2000).

\section{Referências}

ABAURRE, Maria Bernadete M. The interplay between spontaneous writing and underlying linguistic representations. European Journal of Psychology of Education, v. 3, n. 4, p. 415-430, 1988. 
. Horizontes e limites de um programa de investigação em aquisição da escrita. In: LAMPRECHT, Regina (org.). Aquisição da linguagem: questóes e análises. Porto Alegre: EDIPUCRS, 1999. p. 167-186.

AMARAL, Veronica S. do; GONÇALVES, Giovana Ferreira. Produçōes orais e escritas dos ditongos [aj], [ej] e [ow]: dados de São José do Norte/RS. Diadorim, v. 14, p. 127-154, 2013.

BARBOSA DA SILVA, Myrian. Leitura, ortografia e fonologia. São Paulo: Ática, 1981.

BISOL, Leda. O acento e o pé métrico binário. Cadernos de Estudos Lingüísticos, n. 22, p. 69-80, 1992.

A neutralização das átonas. Revista Letras, n. 61 (especial), p. 273283, 2003.

- O alçamento da pretônica sem motivo aparente. In:

COLLISCHONN, Gisela. Português do sul do Brasil: variação fonológica. Porto Alegre: EDIPUCRS, 2009. p. 73-92.

. Harmonização vocálica: efeito parcial e total. Organon, v. 28, n. 54, p. 49-61, 2013.

BRENMAN, Ilan. Até as princesas soltam pum. São Paulo: Brinque-Book, 2008. CAGLIARI, Luiz Carlos. Alfabetização e linguística. São Paulo: Scipione, 2009. CAMARA JR., Joaquim Mattoso. Estrutura da lingua portuguesa. Petrópolis: Vozes, 1970.

FARACO, Carlos Alberto. Linguagem escrita e alfabetização. São Paulo: Contexto, 2012.

FERREIRO, Emilia; TEBEROSKY, Ana. Psicogênese da língua escrita. Trad. Diana Myriam Lichetenstein, Liana Di Marco, Marco Corso. Porto Alegre: Artmed, 1999.

KENSTOWICZ, Michael. Phonology in generative grammar. Cambridge: Blackwell, 1994.

LEAL, Telma Ferraz; ROAZZI, Antonio. A criança pensa... e aprende ortografia. In: MORAIS, Artur Gomes de (Org.). O aprendizado da ortografia. Belo Horizonte: Autêntica, 2000. p. 99-120. 
LEE, Seung Hwa. A regra do acento do português: outra alternativa. Letras de Hoje, v. 29, n. 4, p. 37-42, 1994.

LEMLE, Miriam. Guia teórico do alfabetizador. São Paulo: Ática, 2009.

LIMA, Cinara Miranda; DHEIN, Carla Juliana F.; MIRANDA, Ana Ruth Moresco. Aquisição ortográfica: 'sau' ou 'sal'; 'pego', 'pegol' ou 'pegou'. In: ENCONTRO DO CÍRCULO DE ESTUDOS LINGUÍSTICOS DO SUL, 7, 2006, Pelotas, RS. MATZENAUER, Carmen L. B. et al. (Orgs.). Anais... Pelotas: EDUCAT, 2008. p. 1-8. Disponível em: <http://www.celsul.org.br/ Encontros/07/dir1/6.pdf $>$.

MASSINI-CAGLIARI, Gladis. "Erros" de ortografia na alfabetização: escrita fonética ou reflexôes sobre o próprio sistema de escrita? In: . CAGLIARI, Luiz Carlos. Diante das letras: a escrita na alfabetização. Campinas: Mercado das letras, 1999. p. 121-128.

. CAGLIARI, Luiz Carlos. Diante das letras: a escrita na alfabetização. Campinas: Mercado das letras, 1999.

MENN, Lise; STOEL-GAMMON, Carol. Desenvolvimento fonológico. In: FLETCHER, Paul; MACWHINEY, Brian (Orgs.). Compêndio da linguagem da criança. Porto Alegre: Artes Médicas, 1997. p. 277-295.

MIRANDA, Ana Ruth Moresco. A aquisição ortográfica das vogais do português: relaçóes com a fonologia e a morfologia. Letras, n. 36, p. 151-168, 2008.

. Aspectos da escrita espontânea e da sua relaçáo com o conhecimento fonológico. In: LAMPRECHT, Regina Ritter (Org.). Aquisição da linguagem: estudos recentes no Brasil. Porto Alegre: EDIPUCRS, 2011. p. 263-276.

MOLLICA, Maria Cecília. Influência da fala na alfabetização. Rio de Janeiro: Tempo Brasileiro, 2000.

MONARETTO, Valéria N. de Oliveira. O alçamento das vogais médias pretônicas /e/ e /o/ sem motivaçáo aparente: um estudo em tempo real. Fragmentum, n. 39, p.18-28, 2013.

MORAIS, Artur Gomes de. "Por que gozado não se escreve com u no final?" os conhecimentos explícitos verbais da criança sobre a ortografia. In:

(Org.). O aprendizado da ortografia. Belo Horizonte: Autêntica, 2000. p. 77-98. 
PAIVA, Maria da Conceição Auxiliadora de. Supressão das semivogais nos ditongos decrescentes. In: OLIVEIRA E SILVA, Giselle Machline de; SCHERRE, Maria Marta Pereira (Orgs.). Padróes sociolinguísticos. Rio de Janeiro: Tempo Brasileiro, 1996. p. 217-236.

REGO, Lucia Lins Browne; BUARQUE, Lair Levi. Algumas fontes de dificuldades na aprendizagem de regras ortográficas. In: MORAIS, Artur Gomes de (Org.). O aprendizado da ortografia. Belo Horizonte: Autêntica, 2000. p. 21-41.

SCHWINDT, Luiz Carlos. A regra variável de harmonização vocálica no RS. In: BISOL, Leda; BRESCANCINI, Cláudia (Orgs.). Fonologia e variação: recortes do português brasileiro. Porto Alegre: EDIPUCRS, 2002. p. 161-182.

SILVA, Priscila Rufino da. A hipercorreção na escrita de crianças e adultos em processo de alfabetização. Leitura, n. 47, p. 311-331, 2011.

TEIXEIRA, Shimene de Moraes; GRASSI, Luísa Hernandes; OLIVEIRA, Natália Devantier de; MIRANDA, Ana Ruth Moresco. Uma reflexão sobre os erros ortográficos e sobre a importância da formação teórica para a prática pedagógica de professores de séries iniciais. Verba volant, v. 2, n. 1, p. 78-94, 2011.

TENANI, Luciani; REIS, Marília Costa. "E veveram felizes para sempre": análise de grafias não-convencionais de vogais pretônicas. Verba volant, v. 2, n. 1, p. 22-43, 2011.

VIEIRA, Maria José Blaskovski. As vogais médias postônicas: uma análise variacionista. In: BISOL, Leda; BRESCANCINI, Cláudia (Orgs.). Fonologia e variação: recortes do português brasileiro. Porto Alegre: EDIPUCRS, 2002. p. 127-159.

- As vogais médias átonas nas três capitais do sul do país. In: BISOL, Leda; COLLISCHONN, Gisela. Português do sul do Brasil: variação fonológica. Porto Alegre: EDIPUCRS, 2009. p. 50-72.

ZORZI, Jaime Luiz. Aprender a escrever: a apropriação do sistema ortográfico. Porto Alegre: Artes Médicas, 1998. 


\title{
BETWEEN 'HESTÓRIAS' AND 'PRÍNCEPES', THE OVERCORRECTION IN WRITING FORMS REVEALS WHAT CHILDREN KNOW ABOUT THE LANGUAGE
}

\begin{abstract}
This research has as its objective to analyze, qualitatively, the mistakes caused by overcorrection that were observed in written texts from students from 2nd grade from a elementary school from the city of Bagé/RS/Brazil. Through the data analysis, we observed that mistakes are not aleatory, and that it reveals the linguistic knowledge of the children, in a special way the knowledge about linguistic variation.
\end{abstract}

KEYWORDS: overcorrection; orality/writing; linguistic variation.

Recebido em: 30/03/2015 Aprovado em: 25/09/2015 